\title{
Perancangan Reaction Wheel Inverted Pendulum Sebagai Alat Peraga Sistem Kontrol Berbasis Sistem Kontrol PID
}

\author{
Roche Alimin ${ }^{1 *}$, Joshua Tandio' , Handry Khoswanto ${ }^{3}$ \\ ${ }^{1,2}$ Program Studi Teknik Mesin, ${ }^{3}$ Program Studi Teknik Elektro, Fakultas Teknologi Industri, \\ Universitas Kristen Petra, Л. Siwalankerto 121-131, Surabaya 60236, Indonesia \\ * Penulis korespondensi; E-mail: ralimin@petra.ac.id
}

\begin{abstract}
ABSTRAK
Sebuah sistem kontrol akan lebih mudah dipahami apabila tersedia alat peraga yang dapat digunakan sebagai media pembelajarannya. Reaction wheel inverted pendulum adalah suatu alat yang under-actuation sehingga keberadaan kontroler mutlak dibutuhkan. Ini akan sangat menarik bila digunakan sebagai alat peraga sebuah sistem kontrol. Salah satu aplikasi dari reaction wheel inverted pendulum ini adalah untuk sistem kesimbangan robot humanoid. Dalam perancangan ini dilakukan perancangan fisik alat peraga dan perancangan kontrolernya. Perancangan dimulai dari merancang mekanik alat peraga terlebih dahulu, mulai dari dimensi dan bentuk alat sampai kebutuhan motor. Selanjutnya didesain kontroler yang dapat menyeimbangkan alat secara otomatis. Kontroler yang digunakan berbasis Arduino. Dari hasil pengujian didapatkan bahwa alat peraga reaction wheel inverted pendulum ini dapat berfungsi dengan cukup baik meskipun ada sedikit kekurangannya.
\end{abstract}

Kata kunci: Sistem kontrol PID; pendulum terbalik; roda reaksi; alat peraga otomasi.

\begin{abstract}
A control system will be easier to understand if demo devices are available that can be used as learning media. Reaction wheel inverted pendulum is an under-actuation device so that the existence of a controller is absolutely necessary. This will be very interesting if used as a teaching aid of a control system. One application of this reaction wheel inverted pendulum is for the humanoid robot balance system. In this research project the physical design of the teaching aids and the design of the controller are carried out. The design starts from designing mechanical part first, starting from the dimensions and shape of the tool to the needs of the motor. Furthermore, a controller is designed that can balance the device automatically. The controller used is based on Arduino. The test results show that the reaction wheel inverted pendulum demo device can work quite well even though there is some drawback.
\end{abstract}

Keywords: PID control system; inverted pendulum; reaction wheel; automation demo device.

\section{PENDAHULUAN}

Inverted pendulum adalah sebuah pendulum yang terbalik, dimana pusat massanya berada di atas pusat pivotnya. Sepeda segway merupakan salah satu contoh implementasinya. Inverted pendulum ini dapat digolongkan sebagai sistem yang underactuation, dimana jumlah derajat kebebasan sistem lebih banyak dari jumlah aktuatornya. Hal yang demikian membuat inverted pendulum menjadi sesuatu yang menarik bila digunakan sebagai alat untuk menguji algoritma sistem kontrol.

Dalam proses belajar teknik otomasi terdapat konsep-konsep yang sulit untuk dibayangkan. Oleh sebab itu diperlukan alat peraga yang dapat membantu memberi gambaran tentang konsep-konsep yang dipelajari oleh mahasiswa. Dengan mencoba mengimplementasikan apa yang telah dipelajari oleh mahasiswa di kelas pada alat peraga ini, maka mahasiswa akan dapat lebih mudah memahami materi yang telah diajarkan [1].

Chia membuat robot yang mengikuti garis sebagai alat peraga kontroler PID. Garis yang diikuti oleh robot adalah pita berwarna hitam yang diletakkan pada bidang yang berwarna putih dengan bentuk persegi empat [2]. Alat ini memiliki kelebihan dalam hal mobilitas, tapi memerlukan tempat yang luas.

Gonzalez membuat alat peraga untuk mengaplikasikan kontroler PI yang berbentuk seperti segway. Benda akan cenderung jatuh karena benda bertumpu pada dua roda Motor yang terletak pada 
masing-masing roda berfungsi untuk menyeimbangkan kembali benda tersebut sehingga tidak jatuh [3].

Pada tulisan ini akan dijelaskan desain alat peraga dengan model reaction wheel inverted pendulum untuk mengaplikasikan teknik kontrol. Model ini memiliki satu reaction wheel terletak pada ujung dari sebuah batang, dan pada ujung yang lain adalah poros [4]. Pada perancangan ini dibatasi pergerakan pendulum hanya pada sudut $-5^{\circ}$ sampai $5^{\circ}$, posisi $0^{\circ}$ pada posisi pendulum vertikal. Batasan ini diperlukan karena kontroler PID yang dipelajari masih terbatas pada LTI (Linear Time Invariant). Apabila pendulum hanya bergerak pada sudut yang kecil maka sistem dapat diasumsikan linear [5].

Pengujian alat dilakukan dengan memosisikan Pendulum vertikal dengan roda berada di atas. Kemudian diberi gangguan agar tidak seimbang. Ketika pendulum tidak berada di posisi vertikal, maka pendulum akan berusaha untuk menyeimbangkan dirinya menuju posisi vertikal.

\section{METODOLOGI}

Langkah pertama adalah mendesain dan menentukan parameter-parameter benda yang akan di kontrol dengan menggunakan software Inventor, kemudian membuat modelnya.

Part alat peraga terdiri dari ditunjukkan pada gambar 1:

- Batang (rod) persegi panjang: 1 buah.

- Roda berbentuk cincin: 1 buah

- Dudukan (mounting): 1 buah

Dimensi pendulum ditentukan dengan mempertimbangkan kegunaan alat sebagai alat peraga. Karena benda yang akan dibuat adalah alat peraga maka itu dimensi dari benda ini tidak boleh terlalu besar. Benda harus mudah untuk dibawa dan juga cukup jelas dalam menunjukkan pergerakannya. Benda dibuat dengan menggunakan $3 D$ printer dengan material PLA.

Membuat rangkaian yang terdiri dari sensor accelerometer MPU-6050, mikrokontroler Arduino dan sebuah motor DC. Reaction wheel inverted pendulum memerlukan sensor yang digunakan sebagai masukan agar bisa memberikan umpan balik kepada kontroler. Mikrokontroler dibutuhkan untuk bekerja sebagai "pusat kontrol". Sebuah motor DC digunakan sebagai keluaran yang memberikan torsi pada reaction wheel dan torsi yang terkendali ini akan berfungsi menyeimbangkan inverted pendulum. Rangkaian Elektronika ditampilkan pada gambar 2.

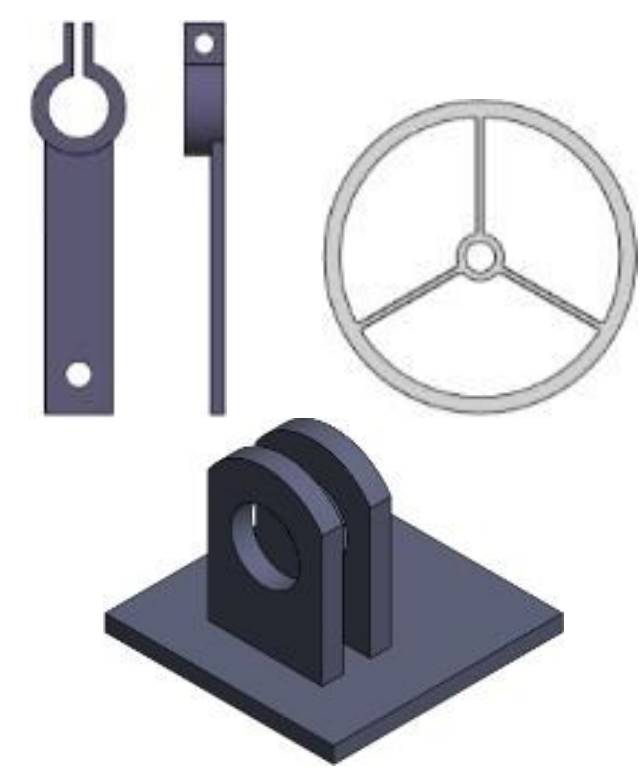

Gambar 1. Part reaction wheel inverted pendulum

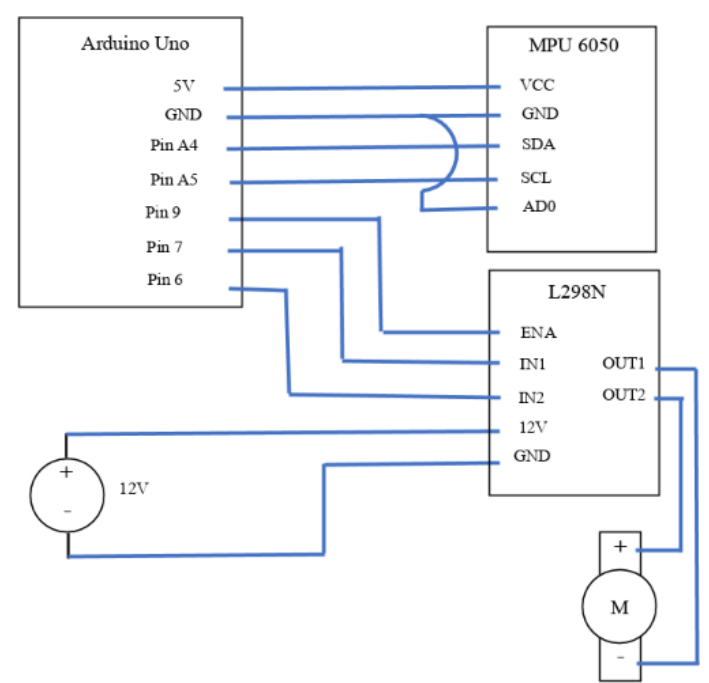

Gambar 2. Rangkaian Elektronika

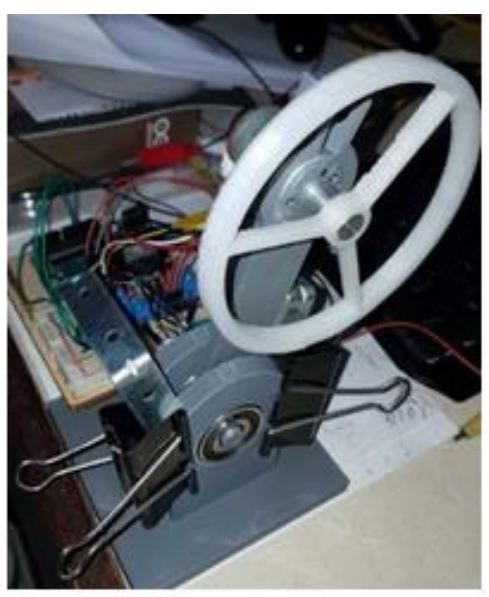

Gambar 3. Reaction wheel inverted pendulum 
Pada gambar 3 ditambilkan Reaction wheel inverted pendulum. Perangkat ini tidak menggunakan rotary encoder sebagai alat yang mengukur kevertikalan pendulum, tetapi menggunakan accelerometer digital.

Spesifikasi Reaction wheel inverted pendulum:

Massa pendulum, $m_{p}=0,02 \mathrm{~kg}$

Massa motor, $m_{m}=0,06 \mathrm{~kg}$

Massa roda, $m_{r}=0,01 \mathrm{~kg}$

Massa total, $m=m_{p}+m_{m}+m_{r}=0,09 \mathrm{~kg}$

Radius motor DC, $r_{m}=0,012 \mathrm{~m}$

Radius roda, $\mathrm{r}=0,05 \mathrm{~m}$

Percepatan gravitasi, $g=9,81 \mathrm{~m} / \mathrm{s}^{2}$

Jarak antara pivot dan pusat massa pendulum, $l_{p}=$ $0,05 \mathrm{~m}$

Jarak antara pivot dan pusat massa roda, $l_{r}=0,1 \mathrm{~m}$ Jarak antara pivot dan Pusat massa total, $l=$ $\left(m_{p} l_{p}+m_{r} l_{r}+m_{m} l_{r}\right) / m=0,0889 \mathrm{~m}=$

Lebar batang, $b=0,025 \mathrm{~m}$

Momen inersia pendulum (batang) pada pusat batang, $J_{p}=1,77 \cdot 10^{-5} \mathrm{~kg} \cdot \mathrm{m}^{2}$

Moment inertia motor pada pusat motor, $J_{m}=$ $4,32 \cdot 10^{-6} \mathrm{~kg} \cdot \mathrm{m}^{2}$

Moment inertia roda pada pusat roda, $J_{r}=$ $2,50.10^{-5} \mathrm{~kg} \cdot \mathrm{m}^{2}$

Moment inertia total, $J_{t}=J_{p}+J_{r}+J_{m}+\left(m_{r} \cdot l_{r}{ }^{2}\right)+$ $\left(m_{p} \cdot l_{p}^{2}\right)+\left(m_{m} \cdot l_{r}^{2}\right)=7,97 \cdot 10^{-4} \mathrm{~kg} \cdot \mathrm{m}^{2}$

Resistansi Armature, $R_{a}=8,6 \mathrm{ohm}$

Konstanta motor, $k_{m}=0,0188 \mathrm{Nm} / \mathrm{A}$

Untuk keperluan desain kontroler dibuat model matematika sesuai dengan data reaction wheel inverted pendulum yang sudah dibuat. Model matematika ini digunakan untuk mendeskripsikan sistem dan memberi gambaran perilaku sistem, yang mana digunakan untuk menentukan dan mendesain parameter kontroler PID-nya. Dalam membuat model matematika ini digunakan metode Lagrangian untuk mendapatkan persamaan gerak dan persamaan motor DC untuk menghubungkan pergerakan benda dan motor DC. Model matematika tersebut dapat digambarkan sebagai berikut.

$J_{t} \ddot{\theta}+J_{r} \ddot{\theta}_{r}=m g l \theta$

$J_{r}\left(\ddot{\theta}_{r}+\ddot{\theta}\right)=k_{m} i_{a}$

$v_{a}=R_{a} i_{a}+k_{m} \ddot{\theta}_{r}$

Model state space berdasarkan persamaan di atas adalah sebagai berikut:

$\dot{x}_{1}=x_{2}=\theta$

$\dot{x}_{2}=\ddot{\theta}=\frac{m g l}{J_{t}-J_{r}} \theta+\frac{k_{m}{ }^{2}}{R_{a}\left(J_{t}-J_{r}\right)} \dot{\theta}_{r}-\frac{k_{m}}{R_{a}\left(J_{t}-J_{r}\right)} u$ $\dot{x}_{3}=\ddot{\theta}_{r}=-\frac{m g l}{J_{t}-J_{r}} \theta-\frac{k_{m}^{2} J_{t}}{R_{a} J_{r}\left(J_{t}-J_{r}\right)} \dot{\theta}_{r}+\frac{k_{m} J_{t}}{J_{r} R_{a}\left(J_{t}-J_{r}\right)} u$

$\dot{x}=\left[\begin{array}{c}\dot{\theta} \\ \ddot{\theta} \\ \ddot{\theta}_{r}\end{array}\right] \quad x=\left[\begin{array}{c}\theta \\ \dot{\theta} \\ \dot{\theta}_{r}\end{array}\right]$

$A=\left[\begin{array}{ccc}0 & & 0 \\ \frac{m g l}{J_{t}-J_{r}} & 1 & \frac{k_{m}{ }^{2}}{R_{a}\left(J_{t}-J_{r}\right)} \\ -\frac{m g l}{J_{t}-J_{r}} & 0 & -\frac{k_{m}{ }^{2} J_{t}}{R_{a} J_{r}\left(J_{t}-J_{r}\right)}\end{array}\right] \quad B=\left[\begin{array}{c}0 \\ -\frac{k_{m}{ }^{2}}{R_{a}\left(J_{t}-J_{r}\right)} \\ \frac{k_{m} J_{t}}{R_{a} J_{r}\left(J_{t}-J_{r}\right)}\end{array}\right]$

$C=\left[\begin{array}{lll}1 & 0 & 0\end{array}\right] \quad D=0$

Kemudian mendesain kontroler untuk menyeimbangkan pendulum dengan menggunakan model kontroler PID dan kontroler PI untuk mencegah motor untuk mencapai kondisi saturasi. Untuk keperluan tuning gain $\mathrm{P}, \mathrm{I}$, dan D digunakan software Matlab dan tuning gain $\mathrm{P}$ dan I dengan metode Ziegler Nichols.

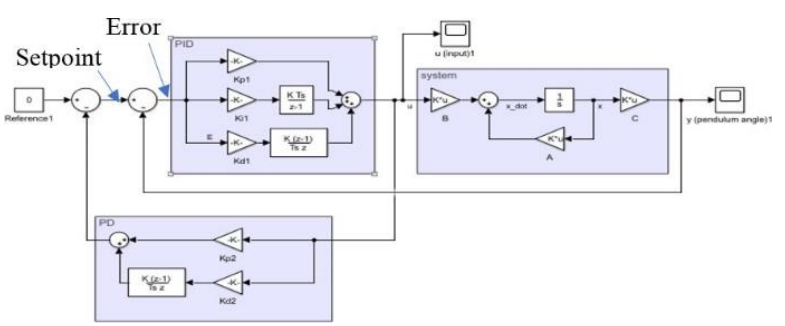

Gambar 4. Blok diagram sistem beserta kontrolernya

Pole dari sistem dan kontroler berada pada sebelah kiri dari sumbu imaginer pada s-plane, tetapi ada satu pole yang berada pada sumbu imaginer. Ini menggambarkan bahwa ada kemungkinan sistem akan dengan mudah berada dalam keadaan critical stable. Setelah parameter kontrol didapat (dengan bantuan Matlab) maka kontroler PID diimplementasikan pada mikrokontroler Arduino. Blok diagram sistem ditampilkan pada gambar 4.

\section{HASIL DAN PEMBAHASAN}

Alat peraga reaction wheel inverted pendulum yang sudah selesai dibuat diuji coba. Tujuannya adalah untuk mengetahui apakah kontroler sudah dapat menyeimbangkan pendulum ke posisi vertikal.

Langkah pengujiannya diawali dengan mengunduh program Arduino yang sudah dibuat ke mikrokontroler Arduino. Kemudian pendulum diposisikan pada posisi vertikal atas sudut $0^{\circ}$. Setelah setimbang di posisi vertical tersebut maka pendulum diberi gangguan berupa pukulan tangan secara pelan. Dan hasil pengujian diindikasikan oleh serial plotter Arduino.

Dari serial plotter Arduino didapatkan grafik berupa hubungan antara posisi pendulum dan tegangan motor DC. Ini ditunjukkan pada Gambar 5. 
Hasil pengujian terlihat pada Gambar 5 menunjukkan ketika pendulum berada pada posisi $-15^{\circ}$ dan kemudian diposisikan pada posisi $0^{\circ}$ (secara manual dengan tangan). Lalu setelah itu pendulum diberi gangguan berupa pukulan pelan, yaitu ketika pada milidetik ke-4800, yang memperlihatkan bahwa pendulum berdeviasi dari posisi tengah akibat gangguan tersebut. Kejadian ini direspon oleh sistem kontrol berupa variasi tegangan yang diberikan ke motor. Dari grafik terlihat bahwa pendulum akhirnya dapat kembali ke posisi tengah (vertikal $0^{\circ}$ ) dan dapat mempertahankan posisinya dari gangguan yang diberikan.

Pengujian step response pada reaction wheel inverted pendulum diberikan untuk melihat karakteristik sistem kontrolnya, baik pada saat transient maupun keadaan sudah steady. Beberapa karakteristik yang ingin diketahui adalah rise time, settling time dan overshoot. Hal ini ditunjukkan pada gambar 5 .

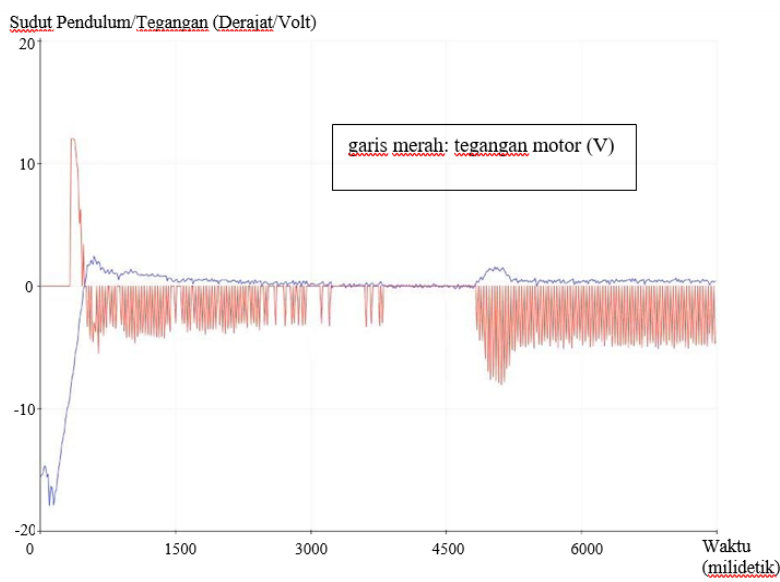

Gambar 5. Grafik hubungan antara posisi pendulum dan tegangan motor DC

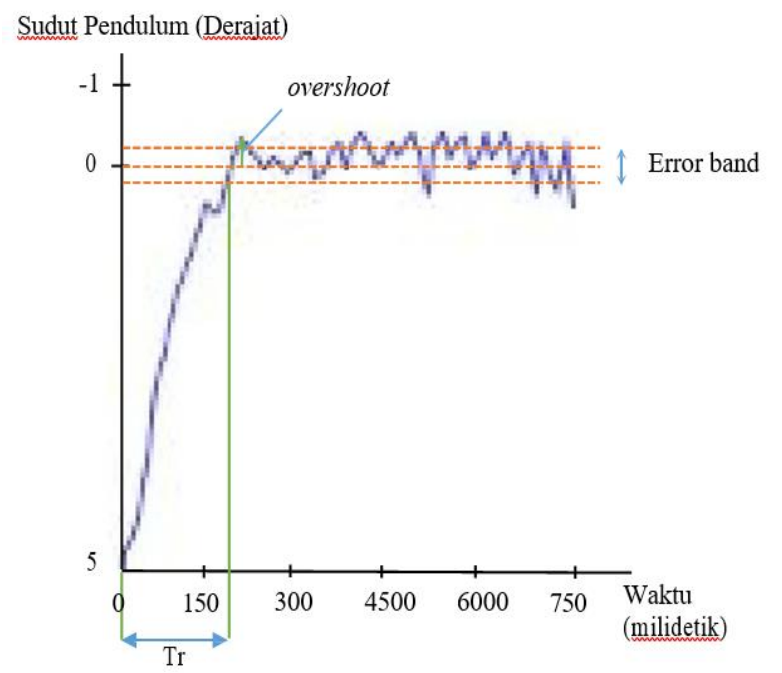

Gambar 6. Step response dari sistem kontrol

Pertama-tama pendulum diposisikan pada posisi $5^{\circ}$, kemudian akibat aksi kontrol pendulum digerakkan oleh motor DC untuk menuju ke posisi 0 .
Hasil respon yang diindikasikan oleh serial plotter Arduino, dan ditunjukkan pada gambar 6.

Dari grafik gambar 6 terlihat bahwa rise time (Tr) adalah 225 milidetik, overshoot sekitar 7\% dan settling time tidak ada.

Pendulum tidak dalam keadaan settling karena pendulum tetap berosilasi keluar masuk error band. Ini kemungkinan disebabkan adanya satu pole dari sistem yang tepat berada pada garis imaginer $s$ plane. Penyebab lainnya adalah adanya gesekan yang cukup signifikan pada poros pendulum. Kecepatan respon yang dibutuhkan oleh sistem masih belum dapat dipenuhi oleh bagian kontrol differential, sehingga bagian kontrol proportional masih terlalu dominan untuk mengatasi gesekan tersebut sehingga menimbulkan sedikit overshoot.

\section{KESIMPULAN}

Dari pengujian step response didapatkan bahwa sistem kontrol yang dirancang masih mempunyai kekurangan yaitu berosilasi ketika seharusnya dalam keadaan steady. Penyebabnya ditengarai akibat adanya gesekan di poros pendulum yang cukup signifikan dan ketidak-sempurnaan model matematika yang dibuat untuk keperluan merancang sistem kontrol PID-nya. Dengan rise time 225 milidetik dan overshoot $7 \%$, sistem reaction wheel inverted pendulum ini masih dapat berfungsi terhadap gangguan deviasi sebesar $5^{\circ}$ yang diberikan.

Alat peraga reaction wheel inverted pendulum ini dapat digunakan sebagai salah satu alat peraga pada kuliah sistem kontrol. Dengan menggunakan mikrokontroler Arduino sebagai kontrolernya, maka konstanta PID dapat dengan mudah divariasi dan dilihat pengaruhnya terhadap kinerja sistem. Ini akan sangat membantu mahasiswa di dalam menelaah konsep sistem kontrol.

\section{DAFTAR PUSTAKA}

[1]. Perrenet ,J.C., Bouhuijs,P.A. and Smits, J.G., 2000, The Suitability of Problem-Based Learning for Engineering Education: Theory and Practice, Teaching In Higher Education, pp. 345358.

[2]. Chia, K.S. and Yap, X.Y., 2016, A Portable PID Control Learning Tool by Means of Mobile Robot, International Journal of Online Engineering, pp. 54-57.

[3]. Gonzalez, C., Alvarado, I. and Munoz La Pena, D., 2017, Low Cost Two-Wheels Self-Balancing Robot for Control Education, IFAC Papers Online, pp. 9174-9179.

[4]. Block, D.J., Astrom, K.J. and Spong, M.W., 2007, The Reaction Wheel Pendulum, Morgan \& Claypool Publishers, the United State of America.

[5]. Olivares, M. and Albertos, P., 2013, Linear Control of The Flywheel Inverted Pendulum, ISA Transactions, 53, 5, pp. 1396-1403. 